\title{
ESTUDO DE IMPACTO AMBIENTAL DE \\ INFRA-ESTRUTURAS URBANAS \\ UMA QUESTÃO DE PRINCÍPIO
}

KLARA ANNA KAISER MORI

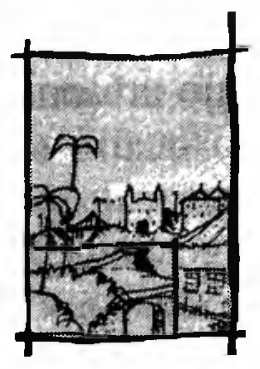

De acordo com a legislação ambiental vigente no Brasil, o licenciamento de um conjunto significativo de empreendimentos de médio e grande portes (entre os quais predominam aqueles de infra-estrutura) compreende, após a elaboração do projeto, as seguintes etapas principais:

a realização de um Estudo de Impacto Ambiental - EIA do projeto, por uma firma contratada pelo empreendedor;

a avaliação do EIA pelo Departamento de Avaliação de Impactos Ambientais da Secretaria do Meio Ambiente - DAIA, com a emissão de um parecer;

o julgamento do processo pelo Conselho Estadual de Meio Ambiente - CONSEMA, tendo por base o EIA, o parecer da DAIA, e assegurada a representação do proponente do empreendimento, culminando com sua aprovação, rejeição ou aprovação com modificações;

encaminhamento do EIA, DAIA e do documento de aprovação do CONSEMA à Companhia de Tecnologia de Saneamento Ambiental/CETESB, e/ou ao Departamento de Proteção dos Recursos Naturais/DPRN, para dar continuidade ao processo de licenciamento.

A rotina acima esboçada, mais que caracterizar a 'capacidade instalada' da máquina burocrática referente à proteção ambiental, visa mostrar o peso dos EIA ao longo desse processo de licenciamento, constituindo uma espécie de representante legal do projeto em apreço.

A intenção deste trabalho é verificar se esta peça-chave da rotina de aprovação acima pode, da maneira como foi concebida, avaliar em suas devidas dimensões e significados as transformações engendradas pelas infra-estruturas produtivas do país. Ou se, e essa é a hipótese subjacente a esta comunicação, os critérios de avaliação que lhe são impostos, fundamentados na segmentação de seu objeto de estudo, acabam por constituí-lo em mais um obstáculo às políticas de formação do espaço. 
Esta verificação impõe a inserção da questão ambiental em seu contexto histórico concreto, marcado pelo processo de urbanização em curso no país.

\section{O PROCESSO DE URBANIZAÇÃO}

Provavelmente devido ao fenômeno impressionante de crescimento urbano que o acompanhou (levando inclusive à formação de algumas das maiores metrópoles mundiais), o processo de urbanização do Brasil freqüentemente tem sido visto como se não passasse de um gigantesco movimento migratório do campo à cidade. Concentrando as atenções em si mesmo, o que esse crescimento urbano extraordinário tem ocultado para muitos é o próprio movimento do qual faz parte integrante, e sem o qual não ganha sentido. Trata-se da transformação do espaço produtivo do país em função das mudanças econômicas engendradas com a industrialização, a saber, a alteração radical de seu perfil produtivo, a ampliação significativa do nível de assalariamento, e, não em último lugar, o reforço da posição do mercado interno em detrimento da produção para exportação.

O processo de urbanização é a formação do espaço desse mercado, e, conseqüentemente, mais que o crescimento das cidades, designa o conjunto de transformações e adaptações às quais todo o território é submetido continuamente, para sua viabilização. Correspondentemente se altera o sentido da expressão espaço urbano, referindo-se à totalidade do espaço desse mesmo mercado ${ }^{1}$.

No espaço urbano assim concebido cabe às infra-estruturas a garantia do livre desempenho das atividades de produção e reprodução social, tornando-se assim largamente responsáveis pela concretização das transformações econômicas que o processo de urbanização pressupõe. É a presença das comunicações, dos transportes, do saneamento, da água, do esgoto, da energia elétrica, da oferta de habitações; de todo o conjunto das instalações, equipamentos e serviços, enfim, que o faz constituir, de fato, um espaço econômico.

Não é por outra razão que, com o início da industrialização, as medidas oficiais voltadas à criação das bases de sustentação do novo padrão produtivo compreendiam, entre outras, os planos referentes à formação do espaço. Ao lado das medidas de regulamentação das condições de assalariamento, das políticas de formação e qualificação da mão-de-obra, das políticas de saúde pública, etc., o período getulista se marcou, dessa forma, também pela alavancagem institucional, a coordenação e o financiamento de um conjunto coordenado de obras de infra-estrutura de âmbito nacional, e por uma política de ajuste dos equipamentos e serviços urbanos às novas escalas requeridas. 
O tema 'infra-estruturação' passou a constituir, desde então, um item sempre presente na agenda do poder público. No entanto, o que dos programas formulados pelos diversos planos governamentais se traduziu efetivamente em obras e realizações se vincula fortemente às flutuações, avanços e recuos da própria política econômica nacional que se seguiu à década de 50 . O resultado dessa inconsistência: a contínua reformulação dos objetivos específicos e dos instrumentos legais, as mudanças constantes de orientação, de prioridades, de prazos, 0 jogo da criação e eliminação das fontes e dos processos de financiamento das infra-estruturas, etc., é o que se pode esperar.

Para exemplificar, observe-se o impacto sobre o espaço urbano da quebra, ou melhor, da interrupção voluntária daquela 'marcha forçada' da economia, que caracterizou grosso modo a década de $70^{2}$. Mesmo se nos ativermos apenas ao âmbito das cidades, as perdas são evidentes: a interrupção do programa de transporte urbano sobre trilhos, a diminuição não só das metas, mas mesmo do ritmo de construção dos metrôs, os descaminhos do programa habitacional, a continuidade da urbanização periférica de baixo padrão, a paralisação do programa de saneamento básico e de abastecimento de água.

Como resultado dessas seguidas mudanças de rumo, as cidades brasileiras, de modo geral, mas de forma mais patente suas maiores metrópoles constituem hoje verdadeiras colchas de retalho no referente à sua infra-estrutura, onde a abrangência das diversas redes dificilmente coincide, onde mesmo sua existência não implica em oferta de serviços ajustada à demanda; um espaço lacunar, enfim, cuja porção efetivamente infra-estruturada se reduz a uma parcela mínima do território urbano.

Em escala regional os exemplos correlatos vão desde a desaceleração do programa energético à interrupção do programa de desenvolvimento da rede de transportes. As limitações de fontes alternativas de energia fazem com que até hoje matas inteiras sejam consumidas para queima direta em fornos à lenha ou para fabricação de carvão vegetal, e a cana-de-açúcar, que se alastrou mesmo arrasando zonas agrícolas de produção muito mais valiosa, hoje vive um impasse. A fragilidade da rede de comunicações, por sua vez, continua a isolar regiões inteiras, sustentando processos produtivos anacrônicos, e favorecendo a manutenção de relações de produção fundamentadas na dependência pessoal direta, quando não propriamente escravagistas.

Sabemos que no Brasil a inexistência de uma estruturação espacial serviu, historicamente, de garantia para a manutenção das formas mais predatórias de exploração do país, um expediente útil para a perpetuação de sua 'vocação agrícola', ou de fornecedor de matérias-primas ${ }^{3}$. Os bloqueios impostos ao desenvolvimento físico-territorial mais qualificado, impedindo ou atrasando a realização 
daquelas transformações dos processos produtivos implicados na industrialização não diferem, até hoje, daquele expediente constituindo o próprio instrumento da economia de rapina sempre praticada pelo país afora, da Amazônia a São Paulo, e realimentando o quadro de penúria econômica e social.

Perante este quadro que gostaria de examinar os temores ambientalistas referentes ao processo de ampliação das infra-estruturas; refletidos, entre outros, na concepção e nas diretrizes dos Estudos de Impacto Ambiental.

\section{OS ESTUDOS DE IMPACTO AMBIENTAL DAS INFRA-ESTRUTURAS}

Dos dezessete itens arrolados no artigo 2 das Resoluções do Conselho Nacional do Meio Ambiente CONAMA ${ }^{4}$, como de licenciamento dependente de Estudo de Impacto Ambiental, com a exceção de cinco, voltados a atividades produtivas, todos os demais se referem a projetos de implantação ou ampliação de infra-estruturas.

A proporção é surpreendente mesmo que a listagem não pretenda ser exaustiva (o texto sugerindo a possibilidade de sua ampliação). Leva a crer que os grandes danos ambientais do país são devidos sobretudo a obras dessa natureza: sistemas de adução de água, de coleta e tratamento de esgotos, de vias, de hidroelétricas, de portos, de assentamentos urbanos. E, em confronto com as formas degradadas da vida urbana (onde mesmo na maior metrópole do país os recursos de água potável se exaurem por falta de uma infra-estrutura adequada para sua captação, coleta, tratamento e distribuição; onde a função abastecimento, de geração de energia, de coleta de esgotos e de assentamentos habitacionais se inviabilizam mutuamente em sua disputa pelos mesmos territórios e corpos d'água; onde a falta de uma rede de transporte de massa adequado amplia gradativamente a proporção do transporte individual, com danos múltiplos ao ambiente urbano) essa preocupação voltada às infra-estruturas não só é estranha, ela chega mesmo a parecer cinismo.

Uma segunda característica marcante do mesmo artigo de lei acima referido é o critério dimensional adotado para selecionar os empreendimentos que venham a impor a realização de EIA. A exposição disso fica mais fácil através de alguns exemplos: se uma estrada de uma pista não implica obrigatoriamente em um Estudo de Impacto, uma de duas ou mais pistas já exige este estudo. Exigem-no também os projetos de urbanização, mas só aqueles acima de 100 ha, usinas de geração de eletricidade se superiores a $10 \mathrm{MW}$, sistemas de captação de água a partir de certo volume. Linhas de ônibus não a requerem, mas ferrovias (incluindo metrô) precisam dela para sua aprovação. 
O que ocorre aqui é nitidamente um duplo equívoco em relação à natureza das próprias transformações esperadas em decorrência dos empreendimentos:

o estabelecimento de uma relação direta entre sua dimensão física e seu impacto potencial, indiferente à gama infinita de variaçōes qualitativas possíveis dentro de um mesmo padrão de grandeza, e desconsiderando ao mesmo tempo que o efeito conjunto de intervenções de menor porte possa ultrapassar de longe a aqueles derivados de um único empreendimento maior. (Trata-se do efeito comparativo, por exemplo, de um conjunto habitacional de 100 ha com dez, cem ou mil loteamentos menores.);

o desvinculamento entre o objetivo de um empreendimento e seu porte levando a entender que a avaliação do impacto de uma obra ou projeto possa se dar de forma independente de demandas econômico-sociais configuradas, das quais constitui uma função. Uma boa prova do absurdo dessa tese ainda é dada por São Paulo, onde é precisamente o desajuste entre a oferta e demanda de transporte de massa que produz alguns dos impactos mais graves ao ambiente urbano (desde os bloqueios da rede viária ao comprometimento de uma série de funções urbanas à poluição atmosférica derivada da crescente utilização do transporte individual).

Acredito que os dois aspectos acima, ao apontar o formalismo e as preconcepções que guiaram o critério de seleção dos empreendimentos sujeitos a EIA sejam suficientes para apontar as dificuldades do ambientalismo para avaliar o significado das intervençōes no espaço. Especificamente no que diz respeito ao impacto das infra-estruturas, por tudo que se procurou expor anteriormente a respeito da função dessas no processo de urbanização, o caminho sugerido pelos EIA parece um contra-senso. Aspecto esse que faz voltar a atenção aos pressupostos teórico-conceituais destes estudos.

\section{OS PRESSUPOSTOS TEÓRICOS DOS ESTUDOS DE IMPACTO AMBIENTAL}

Os três deuses que em A alma boa de Setsuan descem à terra indagando sobre a bondade intrínseca do homem, acabam retornando sem ter realizado seu intento. Nem poderia ser diferente, uma vez que este supunha a avaliação em termos absolutos de algo que só se realiza e adquire significado enquanto uma relação.

Os conceitos de meio ambiente e de impacto ambiental nos quais a metodologia dos EIA se apóia constituem, da mesma forma que aquela 'bondade em si' da peça de Brecht, uma armadilha teórica para sua própria realização. Mas, se aquele enredo é conduzido ao impasse, pela recusa da simplificação encerrada 
tanto numa resposta otimista quanto pessimista para a pergunta, aqui o resultado já está configurado de antemão. Rigorosamente de acordo com o quadro conceitual ambientalista não há como evitar a rejeição franca de qualquer projeto que constitua objeto de um EIA. (Isto se admitirmos que tanto as 'alternativas tecnológicas' quanto o elenco de 'medidas mitigadoras' não passam de formas encobertas da mesma rejeição. $)^{5}$

Para se entender este mecanismo, analisemos brevemente os referidos conceitos $^{6}$. De acordo com o documento que orienta a feitura e apresentação destes estudos, o Conselho Nacional do Meio Ambiente entende por meio ambiente o que se segue:

Meio Ambiente: o conjunto de condições, leis, influências e interações de ordem física, química e biológica, que permite, abriga e rege a vida em todas as suas formas $^{7}$

Fica evidente que, atendo-se a esta concepção, os EIA terão que eliminar automaticamente de suas considerações qualquer raciocínio que envolva a dimensão social da vida reduzindo os processos sociais que configuram o próprio espaço a um conjunto amorfo de leis, influências e interações químicas, físicas e biológicas.

Ainda segundo o mesmo documento, impacto ambiental se define como se segue:

Impacto Ambiental: qualquer alteração das propriedades físicas, químicas e biológicas do Meio Ambiente, causado por qualquer forma de matéria ou energia resultante das atividades humanas que, direta ou indiretamente afetem:

I - a saúde, a segurança e o bem-estar da população;

II - as atividades sociais e econômicas;

III - a biota;

IV as condições estéticas e sanitárias do meio ambiente;

$\mathrm{V}$ - a qualidade dos recursos ambientais ${ }^{8}$.

De forma similar ao que vimos acima, o conceito de impacto ambiental também opera através de uma ruptura, dessa vez entre as transformações do espaço e seus agentes sociais; fazendo com que a sociedade e o meio ambiente compareçam de um lado da oração, como seu sujeito paciente; contrapostos aos dois figuram os fatores potencialmente agressivos, representados pelos projetos em estudo, ou seja, as 'atividades humanas'. Estas, por sua vez, desvinculadas de qualquer fundamentação social, como que surgindo por geração espontânea.

Ora, se o meio ambiente for concebido como mera resultante de determinações naturais, sem nenhum fator social que o qualifique enquanto nosso ambiente, 
obviamente será impossível estabelecer, por seu intermédio, qualquer critério de avaliação de empreendimentos que possam modificá-lo. Resta, como única saída, o registro, a simples constatação desta transformação.

Por outro lado, se o projeto de um empreendimento qualquer não estiver enraizado em alguma necessidade social, se tiver surgido do nada, como a definição acima nos quer fazer crer, tampouco será possível avaliar seu sentido, levandonos de novo a restringir o estudo à determinação do tipo, da intensidade, da abrangência, da duração, etc., das transformações por ele provocadas e apenas enquanto tais.

Mas, se de acordo com o que vimos acima, nem o 'meio ambiente', nem as 'atividades humanas' (os empreendimentos) fornecem elementos válidos para a qualificação das transformações em causa, esta terá que se apoiar obrigatoriamente em critérios externos a este âmbito, de cunho genérico. De fato, é isto que ocorre, como prova a negatividade a priori atribuída a qualquer transformação. Antes de tudo, através da identificação do termo impacto com transformações que afetem o ambiente pelo simples fato de não haver alteração possível que deixe de afetar o ambiente em que se introduz. Isto mesmo sem considerar o significado obviamente negativo do próprio termo impacto, ou o valor a ele atribuído pela expressão medidas mitigadoras de impactos, cuja elaboração constitui etapa de trabalho obrigatória de todo EIA.

\section{CONCLUSÃO}

O ocultamento das causas da urbanização brasileira, das contradições subjacentes ao próprio modelo econômico que a sustenta, bem como do processo conflituoso de seus avanços e retrocessos levam, como visto acima, a uma leitura do padrão do espaço urbano como se sua baixa qualidade decorresse da urbanização 'em si', ou, talvez, de seus 'excessos'. Exemplificado pela desconfiança patente dos EIA em relação às transformações espaciais, que constituem seu foco de interesse, este o terreno em que se articulou, no país, a legislação ambiental.

Não se pretende sugerir, com a colocação acima, que os empreendimentos de que os EIA tratam não produzam impactos negativos: as perdas são inerentes a qualquer processo de transformação. $O$ objetivo visado foi $o$ de mostrar que $o$ partido apriorístico que norteia tais estudos, a valoração negativa de quaisquer fatores de mudança, e em particular aqueles voltados à formação das infra-estruturas não só pode bloquear o encaminhamento de transformações desejáveis, mas simultaneamente, impedir a formulação de críticas mais consistentes de seu objeto de estudo. 
Assim, se os EIA não escaparem daquela visão estática de espaço que não comporta a dimensão de sua própria transformação, e se não romperem o isolamento artificial em que encerram os objetos de seu estudo (os empreendimentos), suas conclusões conduzirão, obrigatoriamente à rejeição de todo e qualquer projeto; pelo simples fato do mesmo implicar em modificações do quadro ambiental. Isso, independentemente das características do padrão econômico-social vigente e de suas contradições, independentemente da efetiva 'qualidade' do ambiente dado, e independente mesmo da manifestação social da necessidade destas transformações. Para se constituir em um instrumento de conhecimento, de crítica, e de planejamento, o desafio dos EIA está no campo que se procurou sugerir aqui: a inserção das transformações do espaço em seu contexto social efetivo e de forma atenta a suas demandas das quais, com maior ou menor representatividade, qualquer projeto é portador.

\section{NOTAS}

(1) A respeito do processo de formação do espaço ver Deák (1985).

(2) A economia brasileira em marcha forçada (Castro e Souza, 1988).

(3) Ver também em contribuição ao estudo da formação do espaço brasileiro (Mori, 1989).

(4) Resolução CONAMA n. 001, de 23/01/86. In: Estudo de Impacto Ambiental EIA, Relatório de Impacto Ambiental RIMA: Manual de Orientaçāo. Governo do Estado de São Paulo, Secretaria do Meio Ambiente, Série Manuais, São Paulo, 1989, p. 29.

(5) Com esta atitude apriorística os EIA constituem uma reprodução perfeita da postura característica dos tecnocratas, apenas com o sinal trocado.

(6) Uma exposição mais detalhada do tema e uma crítica da metodologia dos EIA se encontra em Estudos de Impacto Ambiental EIA algumas considerações (Mori, 1991).

(7) Lei 6.938 de 31 de agosto de 1981, que dispöe sobre a Política Nacional de Meio Ambiente, seus fins e mecanismos de formaçāo e aplicaçāo, e dá outras providências. (in Legislaçāo Básica de Interesse Metropolitano, São Paulo: Emplasa, 1985, p. 77.

(8) Artigo $1^{\circ}$ da Resolução n. 001/86 do CONAMA. In: Estudo de Impacto Ambiental EIA, Relatório de Impacto Ambiental RIMA: Manual de Orientaçāo. São Paulo: Govemo do Estado de São Paulo, Secretaria do Meio Ambiente, Série Manuais, 1989, p. 11.

\section{BIBLIOGRAFIA}

DEAK, Csaba. Rent theory and the price of urban land. Cambridge: King's College, 1985.

Preliminares para uma política urbana. São Paulo, Espaço \& Debates, ano VIII: p. 24, 1988. 
SÃO PAULO. (ESTADO) Estudo de Impacto Ambiental EIA, Relatório de Impacto Ambiental RIMA: Manual de Orientaçāo. São Paulo: Secretaria do Meio Ambiente, Coordenadoria de Planejamento Ambiental, Série Manuais, 1989.

GUNN, Philip. Os processos de planejamento e de projeto urbano. Notas de aula, São Paulo: FAUUSP, 1991.

LUZ, Nícia Vilela. A luta pela industrialização do Brasil. São Paulo: Alfa Omega, 1978, $2^{\mathrm{a}}$ ed., 1961.

MORAES, Antonio Carlos Robert. Geografia pequena história crítica. São Paulo: Hucitec, $2^{\mathrm{a}}$ ed., 1983.

MORI, Klara Kaiser. Contribuição ao estudo da formaçāo do espaço brasileiro. São Paulo, 1989. Dissertação (mestrado) - FAUUSP. . Estudos de Impacto Ambiental EIA algumas consideraçōes. (mimeo.), 1991.

SCHIFFER, Sueli Ramos. Implicações espaciais das principais políticas nacionais: 19551980. Cadernos Técnicos FAUUSP, São Paulo, 1991.

SILVA, Sergio. Expansão cafeeira e origens da indústria no Brasil. São Paulo: Alfa Omega, 1976.

SÓCRATES, Jodete R. et al. A Cidade invade as águas: Qual a questāo dos mananciais? FAUUSP, São Paulo: FAUUSP, 1985.

Legislação básica de interesse metropolitano. Emplasa, São Paulo, 1985 